\title{
Leuprolide/Tamoxifen Regimen
}

National Cancer Institute

\section{Source}

National Cancer Institute. Leuprolide/Tamoxifen Regimen. NCI Thesaurus. Code C10897.

A hormone therapy regimen consisting of leuprolide and tamoxifen that may be used in the treatment of breast cancer. 